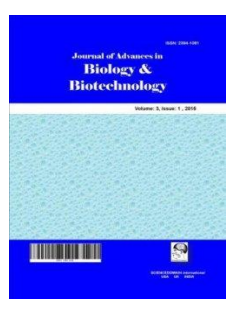

\title{
Effect of Pomegranate Peel Extract on Submandibular Salivary Glands of Streptozotocin- Induced Diabetes in Rats: Histological, Immunohistochemical and Ultrastructural Study
}

\author{
Elham F. Mahmoud ${ }^{1 *}$ and Mahmoud F. Mahmoud ${ }^{2}$ \\ ${ }^{1}$ Department of Oral Biology, Faculty of Oral and Dental Medicine, Suez Canal University, Egypt. \\ ${ }^{2}$ Department of Biological and Geological Sciences, Faculty of Education, \\ Ain Shams University, Egypt.
}

Authors' contributions

This work was carried out in collaboration between both authors. Author EFM designed the study, performed the statistical analysis, wrote the protocol and wrote the first draft of the manuscript. Author

MFM managed the analyses of the study. Authors EFM and MFM managed the literature searches. Both authors read and approved the final manuscript.

Article Information

DOI: $10.9734 / J A B B / 2017 / 34101$

Editor(s):

(1) Prof. Margaret Tzaphlidou, Department of Medical Physics, School of Health Sciences, Ioannina University, Greece.

Reviewers:

(1) Mahfoud Bakli, University Center of Ain, Algeria.

(2) Loai Aljerf, University of Damascus, Syria.

(3) T. Nagamma, Manipal University, India.

Complete Peer review History: http://www.sciencedomain.org/review-history/19579

Original Research Article

Received $13^{\text {th }}$ May 2017

Accepted $12^{\text {th }}$ June 2017

Published $16^{\text {th }}$ June 2017

\begin{abstract}
Purpose: Diabetes mellitus is a significant healthcare problem concern worldwide. It has different pathological effects on body tissues and organs especially on the major salivary glands. Pomegranate considers a native fruit that contains numerous polyphenolic antioxidant ingredients when compared to other fruits and vegetables. The aim of the current study was to explore the biological impact of Pomegranate Peel Extract on streptozotocin induced diabetes in submandibular salivary gland of albino rats.

Methods: 30 male adult albino rats were separated into 3 groups: Group I (control), group II (diabetic group without any treatment), group III (diabetic group + Pomegranate Peel Extract). Diabetes induction was done by single intraperitoneal (i.p.) injection of streptozotocin. Plasma
\end{abstract}


glucose and insulin levels were measured, submandibular salivary glands were isolated and examined histologically using routine Haematoxylin and Eosin (H\&E) stain, immunohistochemically for detection of anti-apoptotic marker, Beta cell lymphoma-2 (BCL2) to investigates the diabetes mellitus effects on both the structure and function of the submandibular salivary gland and ultrastructural investigations of submandibular salivary glands.

Results: The obtained results revealed tissue alterations and common complications in submandibular glands of diabetic rat. While the antioxidant (Pomegranate Peel Extract) treated rats had fewer tissue alterations than untreated animals.

Conclusions: It was concluded that pomegranate peel extract has marked improving effects against diabetic submandibular salivary gland complications.

Keywords: Streptozotocin; submandibular salivary glands; pomegranate peel extract; Bcl-2; EM.

\section{INTRODUCTION}

A chronic metabolic disease characterized by hyperglycemia is the diabetes mellitus (DM). The long term prediction of diabetic patients is dependent on the uniformity of their fasting plasma glucose levels lasting over $126 \mathrm{mg} / \mathrm{dl}$. One of the most stringent health issues in the $21^{\text {st }}$ century is the highly increasing prevalence of diabetes mellitus worldwide. The diabetic patient' number increases more rapidly than predictable. It is estimated that currently 415 million adults are having diabetes worldwide [1]. Actually, two widespread types of the diabetes: type 1 and type 2 diabetes (T1D and T2D). Type 1 is usually immune-mediated in which the diabetic patients have pancreatic $B$ cell demonstrate the cells that undergo programmed cell death (apoptosis) and degeneration, while Type 2 diabetes is a dual disease that arises when the B-cells can be no longer recompense for insulin reluctance by enhancing their insulin excretion [2]. Saliva and salivary glands are believed to be the massive relationship between oral and general systemic health. DM is considered to consolidate the dry mouth (xerostomia), that is a qualitative and/or quantitative deficiency of salivary secretion in the mouth [3]. Diminished salivary outflow can give rises to multiple complexity in the oral cavity by giving permission to exaggerated aggregation of bacteria leading to multiple oral deteriorations, alteration in the food taste, halitosis, abundant caries and extreme thirst (especially at night). Diminished salivary secretion can be result from multiple situations: the salivary glands radiotherapy [4], drugs [5], in addition to autoimmune diseases. $43 \%$ of individuals reported expertise xerostomia, recognized as dry mouth syndrome, as a consequence of the outset of diabetes [6].

The new blood vessels proliferation from original ones is recognized as angiogenesis that supplies enough blood flow and oxygen to growing tissues. The essential cells that are included in the process of angiogenesis are named endothelial cells. The normal functioning angiogenesis participate in important processes: wound healing, development of fetal cells, menstruation and pregnancy [7]. But when the physiological angiogenesis undergoes disturbances, it can lead to multiple human diseases involving ocular disease, diabetic problems, persistent inflammation, cardiovascular diseases, and cancer [8].

Endothelium dysfunction is considered as an essential agent in the vascular disease pathogenesis in diabetic individuals $[9,10,11]$. The functional inner monolayer of the blood vessels is the endothelium, constituting barrier or mediator between the circulating blood in the lumen and the remaining part of the vessel wall. Also, it represents a sensible role in the blood vessels homeostasis.

Apoptosis represents a morphologically prominent shape of programmed cell death; it performs a great role in homeostasis and cellular outgrowth. Homeostasis is the process involved in organization of salivary gland structure when influenced by some stimuli. Salivary glands' epithelial cells DNA fragmentations (apoptosis) were detected with induction of diabetes [12].

The initial gene reported to be included in apoptosis process is the Bcl-2 (B-cell lymphoma 2) and considered as a proto-oncogene that inhibits the cell death instead of activation of cell proliferation $[13,14]$. The individual $\mathrm{Bcl}-2$ protein is encoded in humans by the BCL2 gene, intracellular and integral membrane protein with $26 \mathrm{kD}$ molecular weight. One organizing member of the Bcl-2 family regulating proteins is the $\mathrm{Bcl}-2$ which responsible for adjusting cell death (apoptosis), through inhibiting (anti-apoptotic) apoptosis or inducing (pro-apoptotic). Bcl-2 is 
categorized as an oncogene and is specifically deemed to be remarkable anti-apoptotic protein $[15,16]$.

$\mathrm{Bcl}-2$ is the second constituent of a domain of proteins at first specified in chromosomal translocations including chromosomes 14 and 18 in follicular lymphomas so its term is derived from B-cell lymphoma, 2 [17].

In the last years, there was more concern toward pharmaceutical plants as a perfect origin of ingredients with hypoglycemic effects for diabetes mellitus treatment (37). Pomegranate, Punica granatum L. (Punicaceae), is a Middle East native fruit. Some biological effectiveness such as antibacterial, antioxidant, anti-diabetic and antitumor have been announced for the extracts from various parts of $P$. granatum (peels, flowers, and seeds) $[18,19,20,21]$.

Some studies reported valuable effectiveness of the methanolic extract of pomegranate peel that could prevent histopathological alternations and all oxidative stress that induced in the kidney and liver of female rats. These effects may be attributed to the antioxidant and anti-apoptotic effectiveness of the pomegranate peel extract [22].

Therefore, the purpose of the current study was conducted to estimate the potential preservative actions of pomegranate peel extract versus streptozotocin-induced diabetes and cytotoxic changes of rat submandibular salivary glands via histological, immuno histochemical and ultrastructural investigations.

\section{MATERIALS AND METHODS}

\subsection{Design}

In accordance with the instructions for the care and use of experimental animals by the National research council guide, the study was performed at the animal house of Faculty of Medicine, Kasr-Al Aini. The ethical approval was obtained by Animal Care Unit Centre for the Purpose of Control and supervision on experimental animals at Cairo University.

A total number of thirty adult (4-6 months age) healthy Albino rats, their body weights ranged between 180-220 g were gained from laboratory animal's colony, Faculty of Veterinary Medicine, Cairo University, Egypt. The animals were lived in polycarbonate cages (10 rats / cages) in controlled laboratory environment; they kept at room temperature with a constant 12 hour light / 12 hour dark period; fed an essential balanced diet and water for at least one week before being used in the experiment.

\subsection{Drug}

Streptozotocin (STZ) drug was used in the form of powder and was purchased from Sigma Chemical Company (St Louis, Missouri, USA).

\subsubsection{Preparations of pomegranate peel extract (PPE)}

Fresh ripe granatum fruits were obtained from the native shop. The peel is removed for extraction intent, and then dehydrated for 10 days in shadow before milling by the Biology department, College of Science, Cairo University. The crushed substance $(50 \mathrm{~g})$ is vibrated in absolute methanol $(500 \mathrm{ml})$ for one day at room temperature, then liquidation through four gauze layers. Centrifugation of the filtrate at $8000 \mathrm{rpm}$ for $15 \mathrm{~min}$ followed by gathering the pure supernatant, then evaporation of the methanol at $45^{\circ} \mathrm{C}$ under low pressure in a rotary evaporator. Keeping the crude extract $(23.5 \%, \mathrm{w} / \mathrm{w})$ at $20^{\circ} \mathrm{C}$ until further using was done. Pomegranate peel extract $(500 \mathrm{mg} / \mathrm{kg})$ is given orally in aqueous solution once per day [23].

\subsubsection{Experimental design and induction of diabetes mellitus (DM)}

The animals were distributed into 3 symmetrical groups (10 rats each).

Control group (Group I): 10 rats were intraperitoneally injected with citrate buffer and sacrificed at the end of the experiment.

Group II and group III: 20 rats were undergoing the diabetes induction. Before induction of diabetes, the rats were starved for 12 hours. A single intraperitoneal injection at a dose of $60 \mathrm{mg}$ of Streptozotocin (STZ) / kg body weight was induced the diabetes in rats [24]. In $0.05 \mathrm{~mol} / \mathrm{l}$ citrate buffer, $\mathrm{pH} 4.5$, STZ was freshly dissolved. $48 \mathrm{~h}$ after induction, the blood glucose level was measured from the orbital veins in capillary tubes for confirmation that the animals had become diabetic. If the blood glucose level was higher than $200 \mathrm{mg} / \mathrm{dL}$, the rats were considered diabetic [23]. The ordinary glucose levels ranging from $80-100 \mathrm{mg} / \mathrm{dL}$ were demonstrated in control rats. In this study, the induced diabetes was type I diabetes mellitus (DM). 
Group II (untreated diabetic rats): 10 diabetic rats were included in this group without treatment to the end of the study (one month).

Group III (diabetic rats + PPE): diabetic rats were given pomegranate peel extract (PPE) $500 \mathrm{mg} / \mathrm{kg}$ body weight orally in aqueous solution once per day on the third day (72 h) after STZ injection for one month.

\subsection{Tissue Samples}

After one month of induction of diabetes, from overnight fasting rats blood samples were taken from the rat tail vein in heparinized capillary tubes. Then centrifugation of samples at $1000 \mathrm{~g}$ were done, plasma was gained and frozen at $-20^{\circ} \mathrm{C}$ in polypropylene tubes until inspected. Sacrification of the whole rats was occurred by ether inhalation anesthesia. The submandibular salivary glands were immediately removed with the head extended, fixed in a $10 \%$ formaldehyde for histological, immunohistochemical and ultrastructural examination [25].

i. Histological Examination: for assessment of the general histological structure variations of the submandibular salivary glands of induced diabetes in rats by using Hematoxylin and Eosin stain.

ii. Immunohistochemical Examination: Avidin-biotin peroxidase immunohistochemical reactions were carried out for localization of Beta cell lymphoma-2 (Bcl-2) as anti- apoptotic marker (Sigma Laboratories). The positive results of $\mathrm{Bcl}-2$ immunoreaction were detected by a brown coloration in the cytoplasm of the acinar and ductal epithelial cells [26].

iii. Electron Microscopic Examination: For the electron microscopic examination, the submandibular salivary glands samples were fixed in $5 \%$ phosphate buffered glutaraldehyde for two hours and processed for the Semithin sections that stained with toluidine blue for examination with transmission electron microscope [27].

\subsection{Biochemical Analysis}

\subsubsection{Determination of plasma glucose and insulin}

i- Fasting plasma glucose was determined using an autoanalyzer (Hitachi 747 autoanalyzer, Hitachi, Tokyo, Japan). ii- Insulin level was measured with a chemiluminescence immuno-metric assay using a UniCell DXI 800 analyzer (Beckman Coulter Inc., Fullerton, CA, USA).

\subsection{Morphometric Studies}

The mean number of Bcl-2 immunopositive cells in the salivary gland sections was measured by the image analyzer computer system Leica Qwin 500; Leica, Cambridge, UK). For each group, five specimens were examined. At a magnification of $\times 100$, about 10 non-overlapping fields from each section were measured. The mean value of the number of cells for each slide and the number of $\mathrm{Bcl}-2$ positive cells were gained. By using the image analyzer, the area of $\mathrm{Bcl}-2$ immunopositive cells was adjusted and expressed as area percentage in relation to the area of the standard measuring frame of $118476.6 \mathrm{~mm}^{2}$.

\subsection{Statistical Analysis}

The data were expressed as means \pm standard deviation of the means (SD). Analysis of variance (ANOVA) was performed on the means to detect whether there were significant $(P<0.05)$ differences among the groups. When ANOVA indicated statistical significance, Tukey-Kramer's multiple comparison tests follows up, for intergroup comparisons. SPSS version 12 (Chicago, Illinois, USA) was used for all statistical analyses. The results were considered significant when $P$ value $<0.05$.

\section{RESULTS}

\subsection{Biochemical Results}

\subsubsection{Effects of PPE on fasting plasma glucose and insulin levels in STZ- induced diabetic rats}

As shown in Table 1, the fasting plasma glucose levels were significantly elevated $(P<0.001)$ in STZ treated diabetic rats (group II) as compared to the control rats $(291.6 \pm 8.16 \mathrm{mg} / \mathrm{dl}$ vs $86.05 \pm$ $4.98 \mathrm{mg} / \mathrm{dl}$ respectively). This was accompanied with significant decrease $(P<0.05)$ in plasma insulin levels in STZ-treated rats compared to control rats $(16.2 \pm 1.16$ vs $22.38 \pm 3.46$ respectively, Table, 1). Treatment of STZ diabetic rats with PPE for one month (group III) significantly decreased $(P<0.001)$ fasting plasma 
glucose level by $42 \%$ compared to non-treated diabetic rats $(170.16 \pm 12.09$ vs $291.6 \pm 8.16$ respectively, Table, 1). Meanwhile, PPE treatment in diabetic rats (group III) did not normalize fasting plasma glucose as there was significant difference $(\mathrm{P}<0.001)$ in group III as compared to control group (Table, 1). There was also significant increase $(P<0.01)$ in plasma insulin level in pomegranate treated diabetic rats (group III) by $61 \%$ as compared to non-treated diabetic rats $(26.04 \pm 5.9$ vs $16.2 \pm 1.16$ respectively) with non-significant difference $(P>0.05)$ between group III and control group (Table, 1).

\subsection{Histological Results}

\subsubsection{Group I (control group)}

Histological examination of the Hematoxylin and Eosin (H\&E) stained tissue sections of the submandibular salivary glands from the control albino rats showed the general normal architecture of the major salivary glands, it revealed a single type of acini; serous acini. These acini were small and variable in size. The acini had narrow lumen and lined by pyramidal cells with faint foamy basophilic cytoplasm with flat basally situated nuclei. The duct system was composed of different types of ducts; the intercalated ducts which were small and rounded, lined by cuboidal epithelium with central rounded nuclei were detected in between the acini, the granular convoluted tubules appeared kidney shaped lined by columnar epithelium with eosinophilic cytoplasm and the striated ducts lined by low columnar epithelium with central rounded nuclei and eosinophilic cytoplasm containing prominent basal striations. The excretory ducts were detected in C.T septa between lobes and lobules. They were lined with pseudostratified columnar epithelium with goblet cells. The blood vessels were occasionally seen around these ducts (Fig. 1).

\subsubsection{Group II (untreated diabetic rats)}

Focal loss of salivary architecture, with overcrowding, cytoplasmic vacuolations was detected by histological examination of the submandibular salivary glands of diabetic rats, when compared to the control group, more basophilic stain was revealed. Large, dark and strong basophilic nuclei of the acinar and duct cells were appeared. The cells of parenchyma showed hyperchromatic darkly stained nuclei with relatively regular size and high mitotic activity. Decreased number of granular convoluted tubules was detected with deficiency in its granular content. Some striated ducts appeared with or without lumen at all. Cytoplasmic vacuolation was demonstrated in some striated ducts. The lumen of many striated and excretory ducts appeared filled with stagnant secretion. The dilated blood vessels engorged with red blood cells were mostly associated with the excretory ducts. Wide spaces in between the acini, distortion and loss of some acini and ducts and intra-acinar vacuolations were noticed in the sections. (Figs. 2, 3)

\subsubsection{Group III (diabetic rats+ PPE)}

PPE treated diabetic albino rats' submandibular salivary gland showed that the gland exhibited its somewhat normal general architecture consisted of predominantly serous acini and duct system. No wide spaces in between the acini were observed. No areas of distortion or loss were seen. The serous acini had narrow lumen and lined by pyramidal cells with pale basophilic granular cytoplasm and basal rounded nuclei while some acini had intra- acinar vacuolations. The excretory ducts showed minimal disruption in their pseudo stratified epithelial lining with some flattened dark nuclei. The gland tissues showed less change and nearly like the control group with normal acini (Fig. 4).

Table 1. Effects of PPE treatment on different biochemical parameters in diabetic rats

\begin{tabular}{llll}
\hline Parameters & $\begin{array}{l}\text { Control } \\
\text { group I }\end{array}$ & $\begin{array}{l}\text { Diabetic } \\
\text { group II }\end{array}$ & $\begin{array}{l}\text { Diabetic+PPE } \\
\text { group III }\end{array}$ \\
\hline Fasting plasma glucose $(\mathrm{mg} / \mathrm{dl})$ & $86.05 \pm 4.98$ & $291.6 \pm 8.16^{*}$ & $170.16 \pm 12.09 \#^{*}$ \\
Plasma Insulin $(\mu \mathrm{U} / \mathrm{ml})$ & $22.38 \pm 3.46$ & $16.2 \pm 1.16^{* *}$ & $26.04 \pm 5.9 \$$ \\
\hline Values are expressed as means $\pm S D(n=10$ each group). $P P E:$ pomegranate peel extract. \\
Analysis of variance $($ ANOVA) followed by Tukey-Kramer analysis was used for the comparison \\
between the groups. \\
${ }^{*} p<0.001,{ }^{* *} p<0.05$ vs control group \\
${ }^{*} p<0.001,{ }^{\$} p<0.01$ vs diabetic group
\end{tabular}



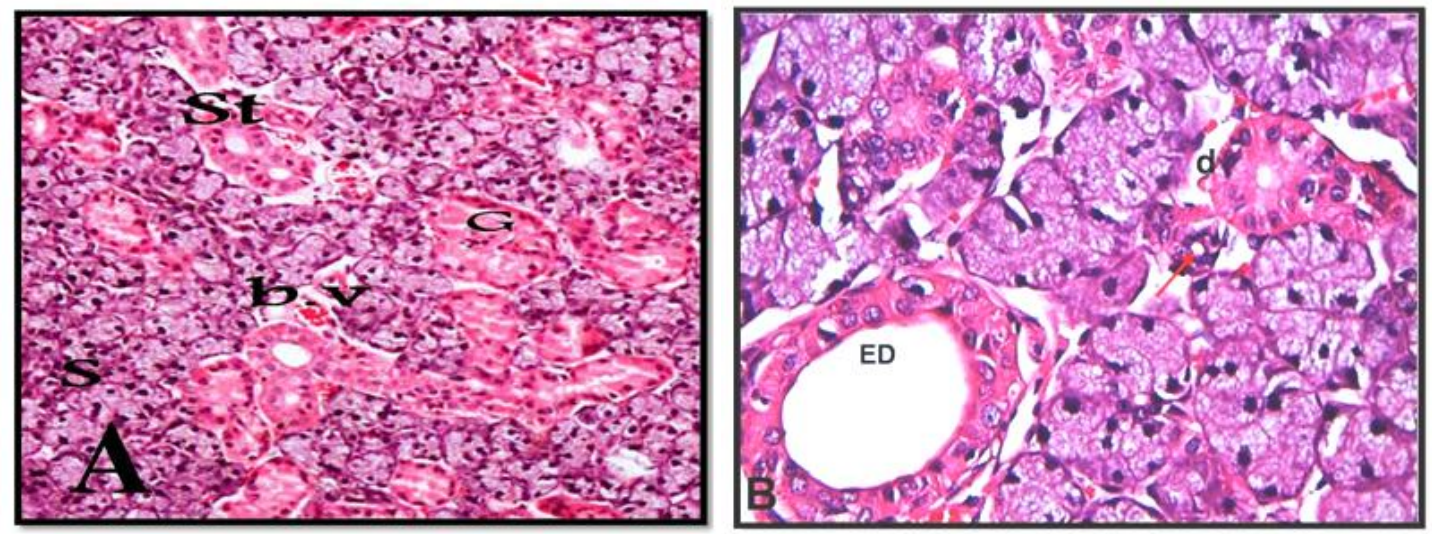

Fig. 1. A photomicrograph of rat submandibular salivary gland of group I (control group) showing: (A) normal acinar architecture (S), striated ducts (St), granular convoluted tubules (G) and blood vessels (bv). (H \& E X200). (B) Serous acini with intercalated ducts in between (arrow), excretory duct with its pseudostratified columnar epithelium (ED). (H \& E X 400)
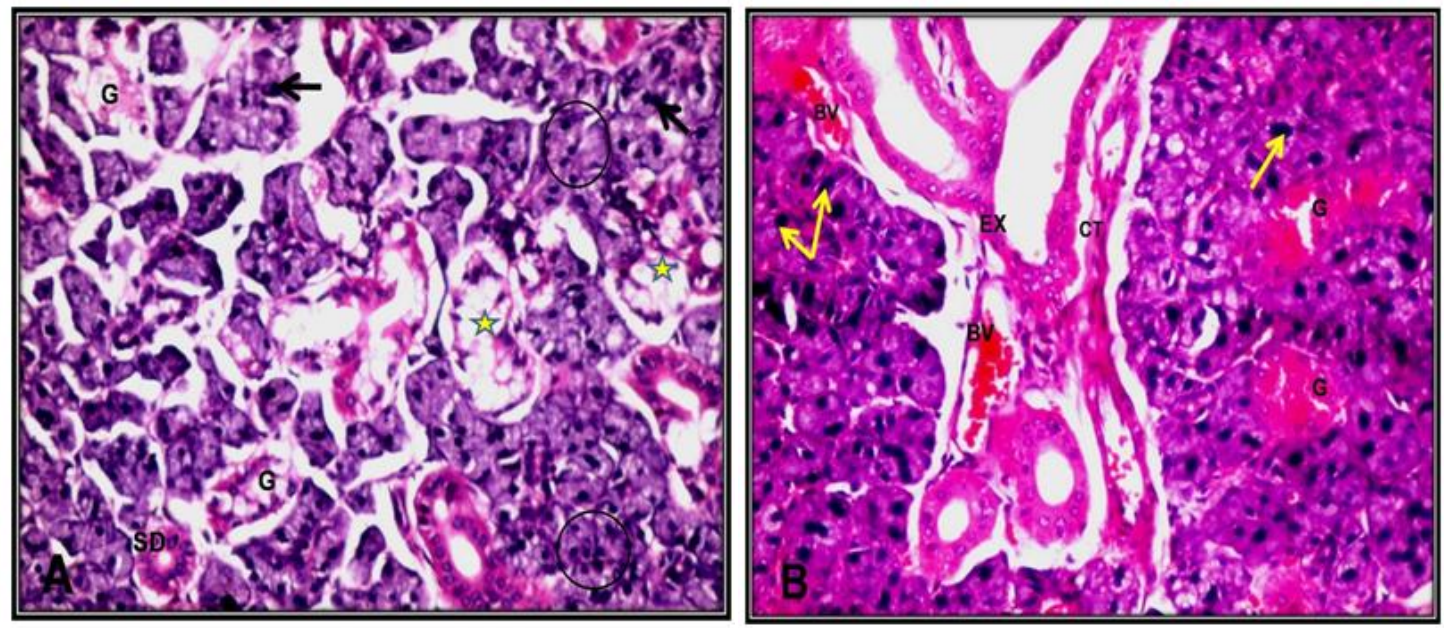

Fig. 2. A photomicrograph of rat submandibular salivary gland of group II (untreated diabetic rats) showing: (A) Shrinkage, overcrowding and loss of acinar architecture

(amalgamation)(circle). Hyperchromatic and polymorphic nuclei (arrows). Decreased granular content of some granular convoluted tubules (G). loss of basal striations in some striated ducts (SD). Some acini and ducts are completely degenerated leaving large spaces (stars). (B): Dilated excretory ducts (EX) with irregular lumens. Hyperchrromatic nuclei (yellow arrows). Increased granular content of some granular convoluted tubules (G). Congested blood vessels (BV) were detected in the thickened and fibrotic connective tissue septa (CT). (H\&E X 200)

\subsection{Immunohistochemical Results}

\subsubsection{Group I (control group)}

The immuno histochemical stained sections of the submandibular salivary gland from the control group rats for detection of $\mathrm{BCL}$ as anti-apoptotic marker showed a strong positive Bcl-2 immuno reaction that appeared as a clear brown color in the cytoplasm of acinar and ductal cells (Fig. 5).

\subsubsection{Group II (untreated diabetic rats)}

The immuno histochemical stained sections of submandibular salivary glands from diabetic rats showed decrease of the Bcl-2 immuno reaction in comparison with that observed in the control group. The immune-reaction appeared faint brown weak positive $\mathrm{Bcl}-2$ immunoreaction in the cytoplasm of acinar and ductal cells (Fig. 6). 

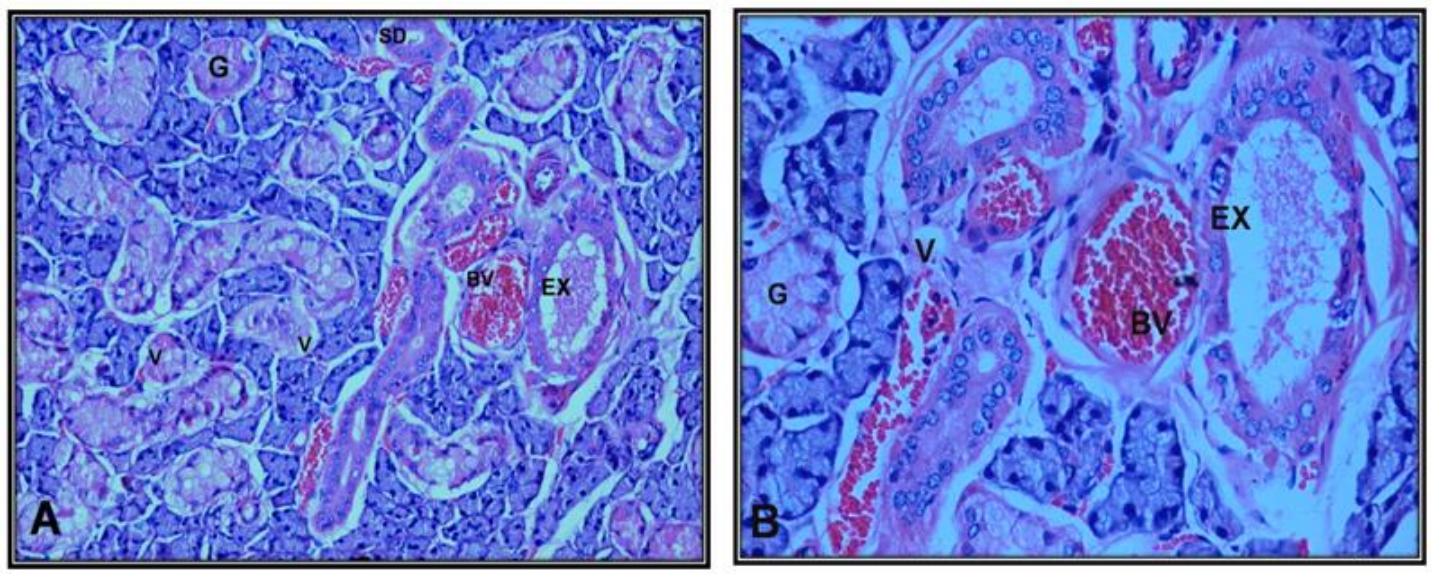

Fig. 3. A photomicrograph of rat submandibular salivary gland of group II (untreated diabetic rats) (A), (B) showing serous acini with variable degrees of cytoplasmic vacuolization (V), decreased granular content of the granular convoluted tubules (G), loss of basal striations in some striated ducts (SD) Dilated excretory duct (EX), with retained secretory material, markedly dilated blood vessels engorged with R.B.Cs. (BV) (H\&E X 200), (H\&E X 400)
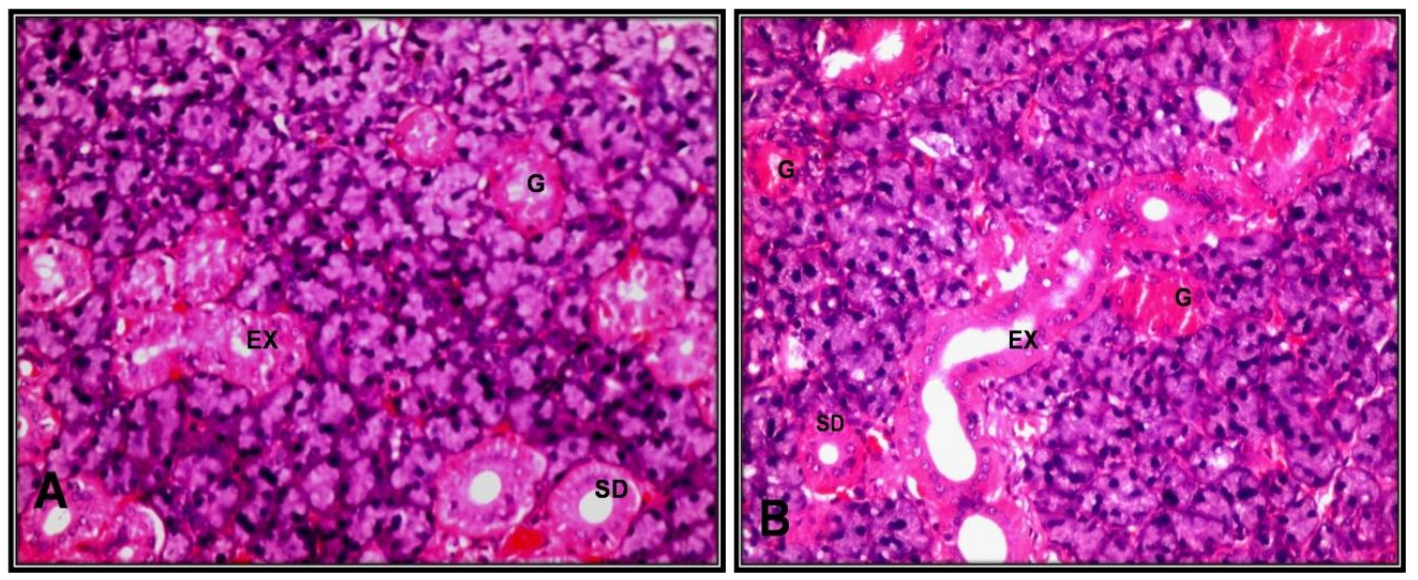

Fig. 4 (A\&B). A photomicrograph of rat submandibular salivary gland of group III (diabetic rats treated with PPE) showing well formed acini and duct lining, intact multiple granular convoluted tubules (G). No congested blood vessels were found. The excretory ducts (EX) had normal cell lining and clear lumen. (H\&E X 200)

\subsubsection{Group III (diabetic rats+ PPE)}

Immuno histochemical stained sections of submandibular glands from diabetic rats after treatment with PPE showed from moderate to strong positive $\mathrm{Bcl}-2$ immuno reaction in the cytoplasm of most of acinar and ductal cells (Fig. 7).

\subsubsection{Image analysis for $\mathrm{Bcl}-2$ expression}

Measuring the optical density of $\mathrm{Bcl}-2$ expression and statistical analysis of the obtained data was done using ANOVA test. It revealed that $\mathrm{Bcl}-2$ expression was highest in group I (control) (mean $\pm S D=62.007 \pm 2.759$ ), decreased in group II (untreated diabetic rats) (mean $\pm S D=43.072 \pm 1.121$ ), while it was moderate to strong in group III (mean $\pm S D=51.513 \pm 3.267$ ). The difference between the studied groups was statistically highly significant as the $p$-value was 0.0001 (Fig. 8).

\subsection{Electron Microscopic Results}

\subsubsection{Group I (control group)}

Ultrastructural examination of the control group of rat submandibular salivary glands showed 
that, the duct system and secretory portions supported by connective tissue stroma. The serous secretory portions of submandibular salivary gland appeared spherical in shape having a central lumen. The serous acinar cell was pyramidal in shape with centrally situated round nucleus. The acinar cell had membrane bound secretoty granules of different electron densities. There was rough endoplasmic reticulum arranged in parallel arrays located basal and lateral to the nucleus. The rat submandibular salivary glands were characterized by special type of ducts named granular convoluted tubules. They were lined by tall columnar cells with round basally located nuclei. A lot of well circumscribed membrane bound electron dense granules of different sizes were observed. The excretory ducts were seen lined by pseudostratified epithelium formed of tall columnar cells and small basal cells that did not reach the lumen so, the nuclei of the duct lining cells appeared at two levels from the basal lamina. Their luminal plasma membranes possessed numerous short Microvilli. The lumen was wide. The duct lining cells had large oval nuclei and numerous mitochondria. Ultrastructurally, striated duct showed that, it was lined by columnar cells having oval nuclei. The striated duct cells were characterized by deep infoldings of the plasma membrane. The apical cytoplasm of the duct lining cells contained numerous mitochondria (Fig. 9).

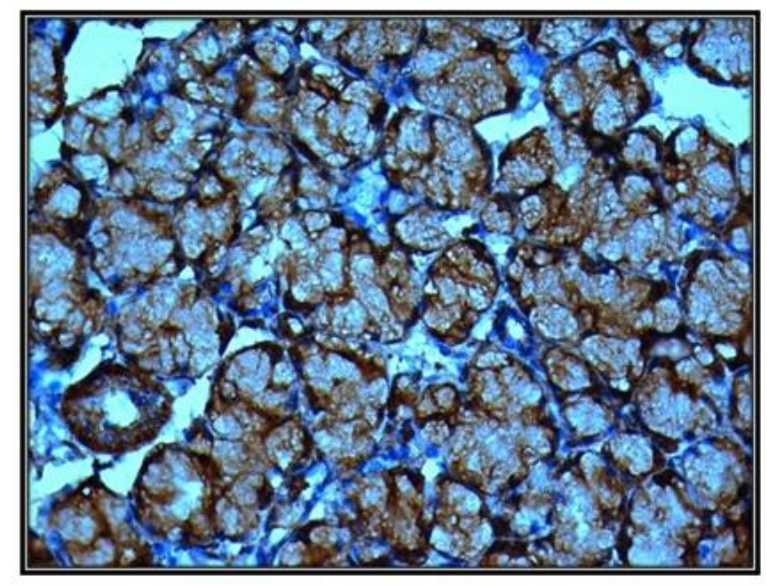

Fig. 5. A photomicrograph of rat submandibular salivary glands of control group showing clear brown positive Bcl-2 immunoreaction in the cytoplasm of acinar and ductal cells. (Mag. X400)

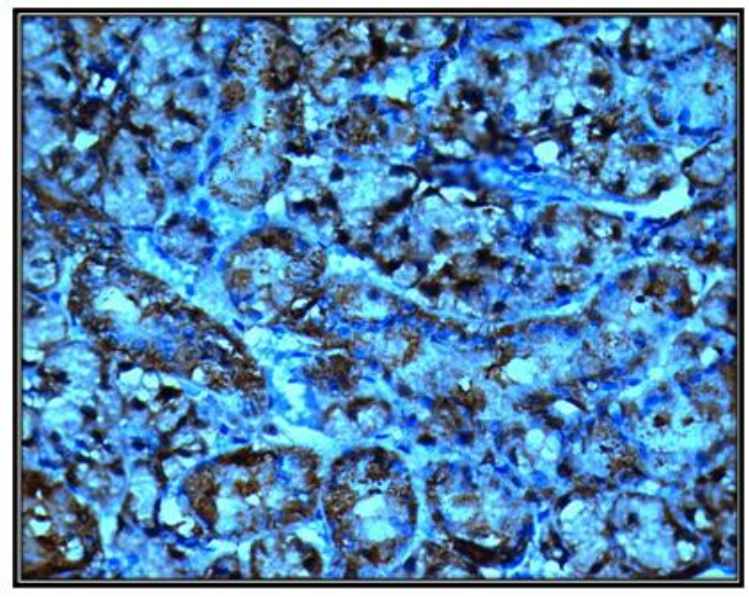

Fig. 6. A photomicrograph of rat submandibular salivary glands of untreated diabetic group showing faint brown weak positive $\mathrm{Bcl}-2$ immunoreaction in the cytoplasm of acinar and ductal cells. (Mag. X400) 


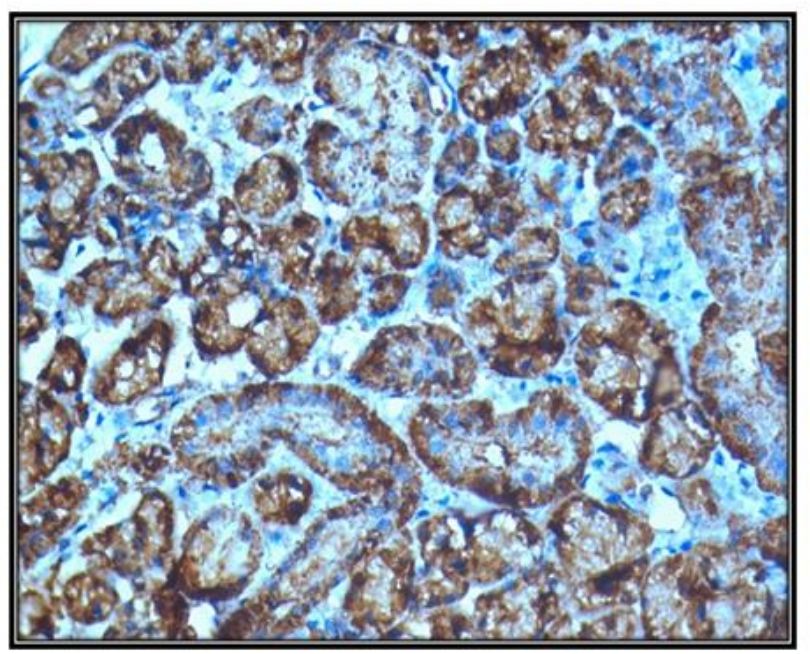

Fig. 7. A photomicrograph of rat submandibular salivary glands of PPE treated diabetic group showing diffuse brown moderate positive $\mathrm{Bcl}-2$ immunoreaction in the cytoplasm of acinar and ductal cells. (Mag. X400)

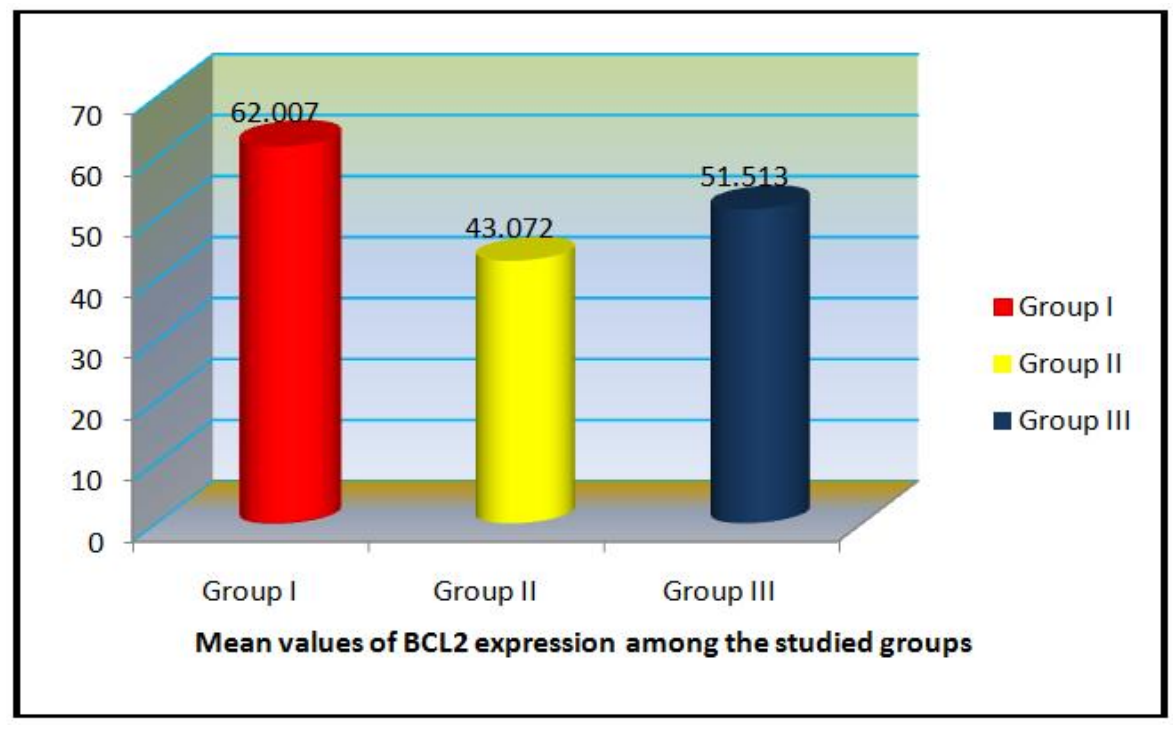

Fig. 8. Mean values of $\mathrm{Bcl}-2$ expression among the studied groups

\subsubsection{Group II (untreated diabetic rats)}

Electron microscopic examination of the submandibular salivary glands of diabetic rats revealed more changes in the ultrastructure of the secretory portions and duct system. The acinar cells showed indentation of the nucleus or appeared shrinked oval electron dense nuclei. The number of secretory granules with different electron densities increased and appeared fused with each other. Slightly dilated rough endoplasmic reticulum was also seen. The secretory cell appeared with degenerative changes manifested as intracytoplasmic vacuolization. The striated duct appeared with nuclei of different sizes and shapes, degenerated mitochondria and loss of the basal infoldings (Figs. 10, 11).

\subsubsection{Group III (diabetic rats+ PPE)}

Electron microscopic examination of the submandibular salivary glands of diabetic rats after treatment with PPE showed that the 
majority of acinar cells appeared more or less as in the control group and having no apparent structural changes. The secretory granules were as in control group and had a tendency to fuse

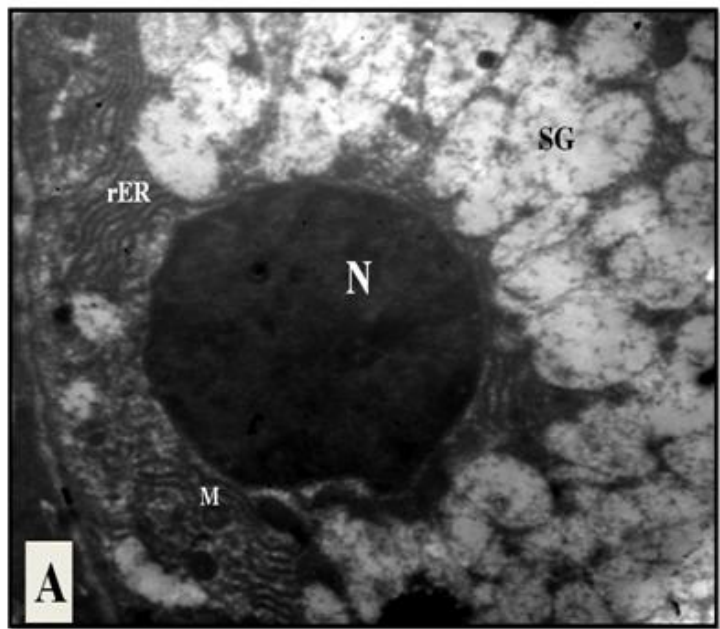

with each other. Decreased structural changes in the mitochondria and slightly dilated rough endoplasmic reticulum was also seen (Fig. 12).

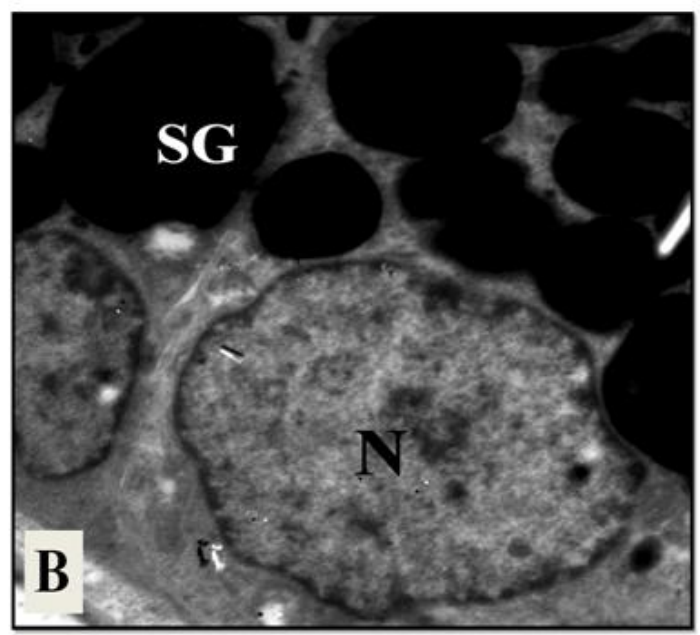

Fig. 9. An electron micrograph of rat submandibular salivary gland of group I (control group) showing part of the secretory portion having basally situated nucleus (N) surrounded by parallel arrays of rough endoplasmic reticulum ( $r E R)$, mitochondria (M) and variable sized membrane bound secretory granules of different electron densities (SG). (X 2000). (B): granular convoluted tubules showing basally situated nuclei $(\mathrm{N})$ and electron dense secretory granules of different sizes (SG). (X 2000)
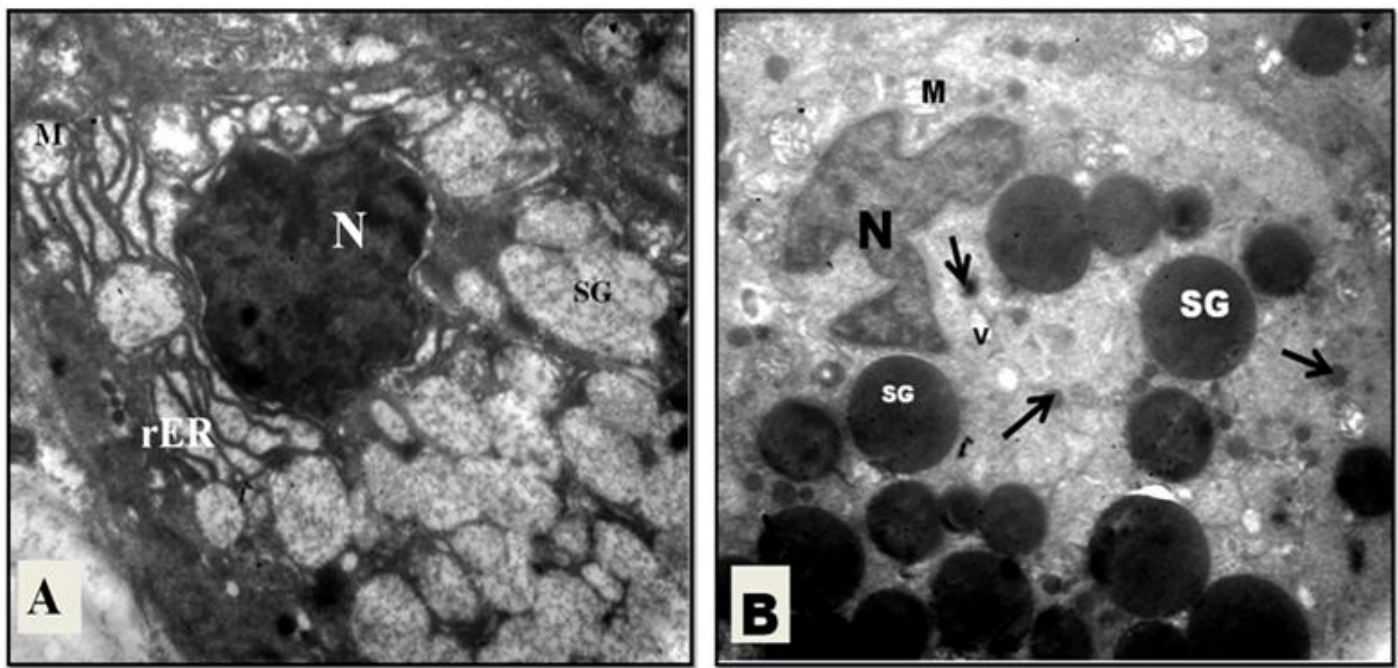

Fig. 10. (A). An electron micrograph of rat submandibular salivary gland of group II showing acinar cell with irregular shaped electron dense nucleus $(\mathrm{N})$, slightly dilated rough endoplasmic reticulum (rER) and electron lucent secretory granules (SG) (X 2000). (B). granular convoluted tubules of pyknotic, shrunked nucleus (N) surrounded by degenerated organelles, electron dense secretory granules of different sizes (SG), intracytoplasmic vacuolization (V) and numerous secondary lysosomes (arrows) (X 2000) 

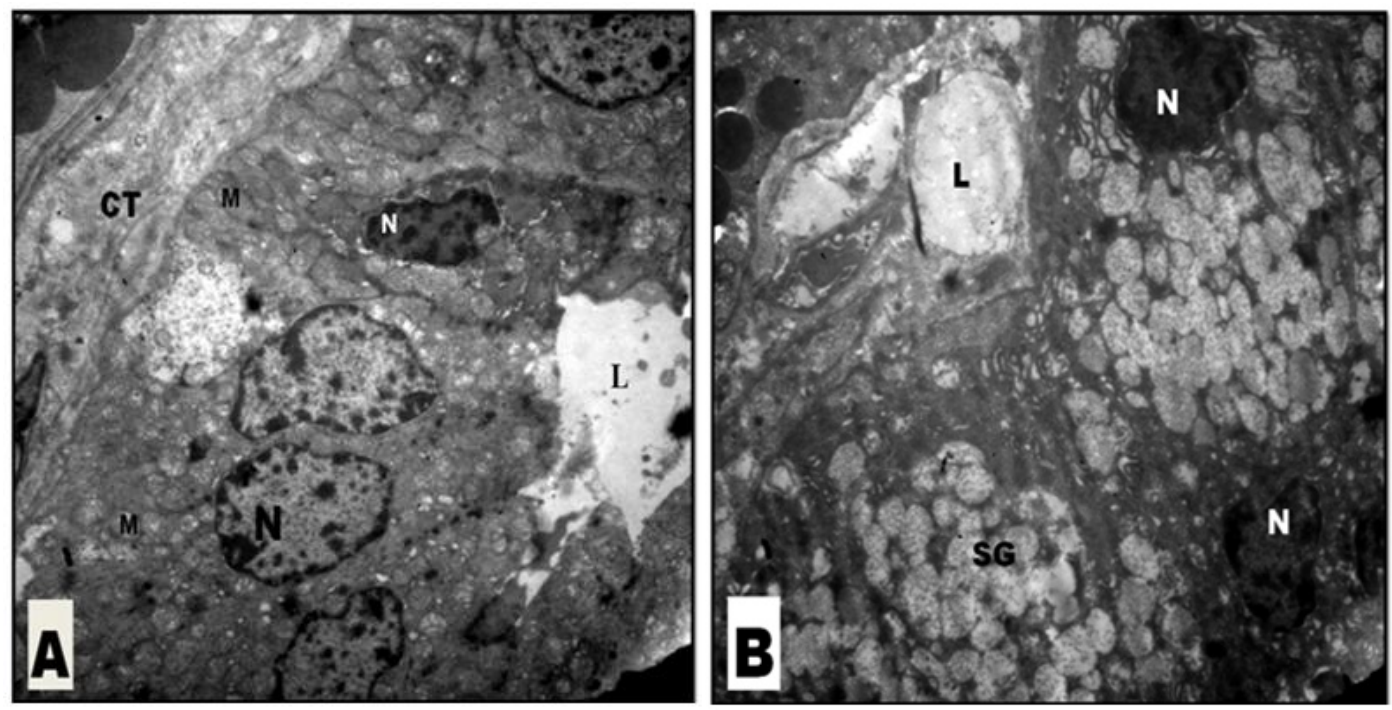

Fig. 11. An electron micrograph of rat submandibular salivary gland of group II showing (A) Degenerative changes of the striated duct manifested as: loss of basal infoldings, degenerated mitochondria (M), stagnation of secretion in the lumen (L) and Nuclei of different sizes and shapes (N) (X 1000). (B) Secretory portion showing increased secretory granules (SG), shrinked electron dense nuclei $(N)$ and stagnation of secretion (L). (X 1000)
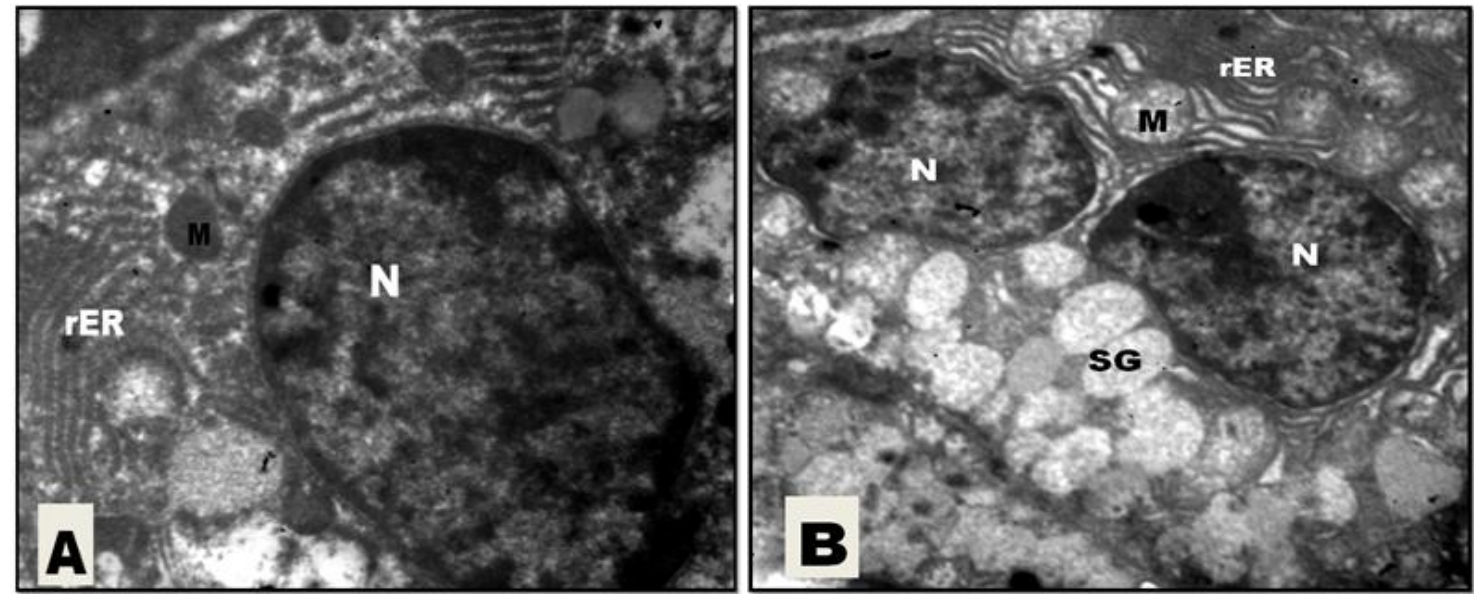

Fig. 12(A,B): An electron micrograph of rat submandibular salivary gland of group III showing that the majority of acinar cells appeared more or less as in the control group and having no apparent structural changes. Slightly dilated rough endoplasmic reticulum (rER).Decreased degenerative changes in the mitochondria (M) that surrounded the basally located nuclei (N). Variable sized membrane bound secretory granules of different electron densities (SG).(X 3000). (X 2000)

\section{DISCUSSION}

Submandibular salivary glands secrete a large amount of saliva, saliva have an essential role in maintaining oral tissues healthy. Hypofunction or dysfunction of the salivary glands will have an impairment effect on the oral tissues [28]. This hypofunction may be happened due to drugs, or systemic disease such as diabetes [29]. Diabetes cause many oral complications such as periodontitis, hyposalivation, taste alteration and halitosis $[30,31]$. The most significant risk factor of diabetes is hyperglycemia. Hyperglycemiamediated apoptosis contributes to the damage of 
targeted organs by increasing the oxidative stress, so adequate control of blood glucose levels, can prevent or even delay the onset of diabetes-related complications [32].

In this study, pomegranate peel extract (PPE) treatment in diabetic rats for 4 weeks significantly reduced STZ-induced high blood glucose levels, and significantly elevated plasma insulin levels as compared to non-treated STZ diabetic rats. These findings suggest a significant antihyperglycemic effect of PPE in diabetic rats which are in agreement with the findings of study [29], where the researchers found that PPE led to significant reduction of blood glucose in STZ induced diabetes in rats. On the contrary, pomegranate peel did not exert significant hypoglycemic effect in alloxan induced diabetic rats as mentioned by researchers [33]. They explained this apparent discrepancy between pomegranate peel and their extract as possibly due to a compound in pomegranate peel with hypoglycemic effects that, in extract form, was more concentrated and therefore more effective in lowering blood sugar than the peel form.

The antidiabetic effect of the peel of pomegranate may be, partly, due to their positive effect on glycogen synthesis in liver, skeletal muscle and heart muscle, and partly, due to the insulin-like or insulin releasing action of the ingredients present in the peel of the plant [34]. The compounds that present in pomegranate peel, such as ellagic, gallic and ursolic acid, have been identified as having anti-diabetic actions [35]. Also, the presence of one or more bioactive antihyperglycemic principles, such as flavonoids, isoflavones, and their synergistic effects [36] are known to be natural antioxidants and thus protecting the existing $\beta$-cells from dying by their free radical scavenging action [37]. The increased plasma insulin levels in pomegranate treated diabetic rats in the present study suggested that the PPE might have stimulated insulin secretion from surviving pancreatic $\beta$-cells and thus blood glucose is controlled.

Our histological results revealed many degenerative changes in the parenchymal element of the submandibular glands as cytoplasmic vacuolation, pyknotic nucleus and focal loss of salivary architecture in the diabetic rats. These findings were in accordance with study [20], that revealed the changes that occurred in the parotid gland of diabetic rats to oxidative stress (liberation of nitric oxide, lipid peroxidation, generation of free radicals, decreased levels of catalase and glutathione peroxidase, protein glycosylation, as well as DNA single-strand breaks) that increased in diabetes. In the present study, pomegranate peel extract treated group had less vacuolation in the cytoplasm of acini cells and less degeneration in the salivary structures with regeneration of the normal salivary architecture supported by normal positive $\mathrm{Bcl}-2$ immunoreaction. At the ultrastructural level, the present observations revealed improving the general structural architecture of the parenchymal elements of the submandibular salivary gland after the pomegranate peel extract therapy. These findings are in agreement with many studies in recent years that demonstrated a correlation between the role of pomegranate peel extract and regulating vital cellular functions, including cell proliferation and differentiation and its potent antioxidant activity and free radical scavenging capability [38].

Regarding the immune-histo-chemical examination, the submandibular salivary glands stained sections of control group, showed a positive $\mathrm{Bcl}-2$ immunoreaction that appeared as a brown color in the cytoplasm of acinar and ductal cells. Whereas most tissue sections in the experimentally induced diabetic group showed decrease of the $\mathrm{Bcl}$ - immunoreaction in comparison with that observed in the control group. These results were agreed with that previously proved, whereas the Bcl-2 (an antiapoptotic protein) was initially inhibit apoptosis by prohibiting cytochrome-c release from the mitochondria and hyperglycaemia caused down regulated expression of $\mathrm{Bcl}-2$ and increased $\mathrm{Bax}$ proteins were detected in diabetic rats $[3,39]$. In the current study, the pomegranate peel extract treated diabetic albino rats' submandibular salivary gland tissue somewhat exhibited its normal histological general architecture by H\&E, ultrastructural investigations and diffuse positive Bcl-2 immunoreaction. The proposed mechanisms by which the antioxidants protect the cells from oxidative stress were including, remove the free radicals in scavenge manner and were promote the activity of the free radicals [40].

\section{CONCLUSION}

In summary, this study revealed that the induction of diabetes could stimulate sever structural changes in the rat submandibular salivary glands. These changes could be slightly diminished by associated management of pomegranate peel extract, so, it is recommended 
that attention should be focused on pomegranate as a significant protective antioxidant, antiinflammatory and anti-diabetic agents based on the present findings. Because of all these objectives and advantages, the employment of pomegranate in general as table fruit can be recommended in human nourishment.

\section{COMPETING INTERESTS}

Authors have declared that no competing interests exist.

\section{REFERENCES}

1. International Diabetes Federation. IDF Diabetes Atlas, $7^{\text {th }}$ Edn. Brussels, Belgium. International Diabetes Federation. 2015; 144.

2. Khan MA, Thempson CS, Calvert RC, Mikhalidi DP, Morgan RJ. Decreased urinary bladder apoptosis in a rabbit model of diabetes mellitus. Urol Res. 2002;1:7983.

3. El-Abd, Shereen S, Ibrahim, Marwa A. Effect of sodium fluoride on the oviductal mucosa of adult albino rats and the possible protective role of pomegranate peel extract. The Egyptian J. of Histology. 2016;39(2):191-202.

4. Hany, Rania. Effect of aqueous extract of basil (Ocimum basilicum) leaves on nephro toxicity induced by adriamycin in male rats: Histological and immune histochemical assessment. Int. J. of Applied and Pure Science and Agriculture. 2017;3(3):99-109.

5. Wijers OB, Levendag PC, Braaksma MM, et al. Patients with head and neck cancer cured by radiation therapy: A survey of the dry mouth syndrome in long-term survivors. Head \& Neck. 2002;24(8):737747.

6. Sreebny LM, Yu A, Green A, et al. Xerostomia in diabetes mellitus. Diabetes Care. 1992;15:900-904.

7. Xue Y, Lim S, Brakenhielm E, Cao Y. Adipose angiogenesis: Quantitative methods to study microvessel growth, regression and remodeling in vivo. Nat Protoc. 2010;5:912-20.

8. Shadi, Rasha S, El-Zainy, Medhat A, Ameen, Reham M, Abdel Fattah, Dina S. Possible effects of mesenchymal stem cells on submandibular salivary glands of streptozotocin induced diabetic albino rats: Histological and immune histochemical study. Ain Shams Dental Journal. 2014; 17(3):47-58.

9. Stehouwer CDA, Lambert J, Donker AJM, Van Hinsbergh VWM. Endothelial dysfunction and pathogenesis of diabetic angiopathy. Cardiovascular Research. 1997;34(1):55-68.

10. Schalkwijk CG, Stehouwer CDA. Vascular complications in diabetes mellitus: The role of endothelial dysfunction. Clinical Science. 2005;109(2):43-159.

11. Lu QL, Abel P, Foster CS, Lalani EN. Bcl2: Role in epithelial differentiation and oncogenesis. Hum Pathol. 1996;27:10210.

12. Aljerf, Alhaffar. Salivary distinctiveness and modifications in males with diabetes and Behçet's disease. Biochemistry Research International. 2017;12.

13. Li A, Ojogho O, Escher A. Saving death: Apoptosis for intervention in transplantation and autoimmunity. Clinical \& Developmental Immunology. 2006; 13(2-4):273-82.

14. Sharma B, Balomajumder C, Roy $P$. Hypoglycemic and hypolipidemic effects of flavonoid rich extract from Eugenia jambolana seeds on streptozotocin induced diabetic rats. Food Chem Toxicol. 2008;46(7):2376-83.

15. Afaq F, Saleem M, Krueger CG, Reed JD. Mukhtar H. Anthocyanin- and hydrolysable tannin-rich pomegranate fruit extract modulates MAPK and NF-kappa B pathways and inhibits skin tumorigenesis in CD-1 mice. Int $\mathrm{J}$ Cancer. 2005;113: 423-433.

16. Bagri $P$, Ali $M$, Aeri $V$, Bhowmik M, Sultana S. Antidiabetic effect of Punica granatum flowers: Effect on hyperlipidemia, pancreatic cells lipid peroxidation and antioxidant enzymes in experimental diabetes. Food and Chemical Toxicology. 2009;47:50-54.

17. Belal SKM, Abdel-Rahman AH, Mohamed DS, Osman $\mathrm{HH}$, Hassan NA. Protective effect of pomegranate fruit juice against Aeromonas hydrophila-induced intestinal histopathological changes in mice. World Applied Sciences J. 2009;7(2):142-152.

18. Abdel Moneim AE, Othman MS, Mahmoud SM, El-Deib KM. Pomegranate peel attenuates aluminum-induced hepato-renal 
toxicity. Toxicol Mech Methods. 2013; 23(8):624-33.

19. Lapornik B, Prosjek M, Wondra AG. Comparison of extracts prepared from plant by-products using different solvents and extraction time. J. Food Eng. 2005; 71:214-22.

20. Chen C, Zhang Y, Sheng X, Huang C, Zang YQ. Differentiation of embryonic stem cells towards pancreatic progenitor cells and their transplantation into streptozotocin-induced diabetic mice. Cell Biol Int. 2008;32:456-461.

21. Wu KK, Huan Y. Streptozotocin-induced diabetic models in mice and rats. Curr Protoc Pharmacol. 2008;18(40):547154714.

22. Bancroft JD, Gamble M. Theory and practice of histological techniques. $5^{\text {th }}$ ed. London; New York, Churchill Livingstone. 2002;63-100:125-138 and 679-701.

23. Al-Refai AS, Khaleel AK, Ali S. The effect of green tea extract on submandibular salivary gland of methotrexate treated albino rats: Immunohistochemical study. J. Cytol Histol. 2014;5:212.

24. Proctor GB, Carpenter GH. Regulation of salivary gland function by autonomic nerves. Autonomic Neuroscience. 2007; 133:3-18.

25. Fedirko NV, Kruglikov IA, Kopach OV, Vats JA, Kostyuk PG, Voitenko NV. Changes in functioning of rat submandibular salivary gland under streptozotocin-induced diabetes are associated with alterations of $\mathrm{Ca} \mathrm{2+}$ signaling and $\mathrm{Ca} 2+$ transporting pumps. Biochimica et Biophysica Acta (BBA)Molecular Basis of Disease. 2006; 1762:294-303.

26. Shrimali L, Astekar M, Sowmya GV. Correlation of oral manifestations in controlled and uncontrolled diabetes mellitus. International Journal of Oral and Maxillofacial Pathology. 2011;2:24-7.

27. Chandna S, Bathla M, Madaan V, Kalra S. Diabetes mellitus-a risk factor for periodontal disease. Internet $J$ Fam Practice. 2010;9.

28. Rouhi SZT, Sarker MMR, Rahmat A, Alkahtani SA, Othman F. The effect of pomegranate fresh juice versus pomegranate seed powder on metabolic indices, lipid profile, inflammatory biomarkers, and the histopathology of pancreatic islets of Langerhans in streptozotocin-nicotinamide induced type 2 diabetic Sprague-Dawley rats. BMC Complementary and Alternative Medicine. 2017;17:156.

29. Aljerf, Mashlah. Characterization and validation of candidate reference methods for the determination of calcium and magnesium in biological fluids. Microchemical J. 2017;132:1-422.

30. Jelodar G, Mohsen M, Shahram S. Effect of walnut leaf, coriander and pomegranate on blood glucose and histopathology of pancreas of alloxan induced diabetic rats. Afr J Tradit Complement Altern Med. 2007; 4(3):299-305.

31. Das S, Sarma G. Antidiabetic action of ethanolic extracts of Punica granatum Linn. In alloxan induced diabetic albino rats. S. J. Pharm Sci. 2009;2(1):14-21.

32. Banihani $S$, Swedan $S$, Alguraan $Z$. Pomegranate and type 2 diabetes. Nutr Res. 2013;33(5):341-8.

33. Manoharan S, Kumar R, Anish, Mary A, Linsa, Singh RB, Balakrishnan S, Silvan S. Effects of Punica granatum flowers on carbohydrate metabolizing enzymes, lipid peroxidation and antioxidants status in streptozotocin induced diabetic rats. The Open Nutraceuticals Journal. 2009;2:113117.

34. Halawa A, Mohamed D, Obeid R. Capsaicin induced histological and ultra structural changes in the sub mandibular salivary gland of albino rats. Future Dental J. 2016;2(1): 22-27.

35. Hidayat $M$, Tahir $M$, Shoro AA. Melatonin preserves the morphology of parotid gland damaged by streptozotocin induced diabetes. J Postgrad Med Inst. 2014; 28:128-32.

36. Ismail T, Sestili P, Akhtar S. Pomegranate peel and fruit extracts: A review of potential anti-inflammatory and antiinfective effects. J. Ethnopharmacol. 2012; 143(2):397-405.

37. Allen DA, Yaqoob MM, Harwood SM. Mechanisms of high glucose-induced apoptosis and its relationship to diabetic complications. Journal of Nutritional Biochemistry. 2005;16(12):705-713.

38. Ricci C, Pastukh V, Mozaffari M, Schaffer SW. Insulin withdrawal induces apoptosis via a free radical mediated mechanism. Canadian Journal of Physiology and Pharmacology. 2007;85(3-4):455-464. 
39. Kaur G, Jabbar Z, Athar M, Alam MS. Punica granatum (pomegranate) flower extract possesses potent antioxidant activity and abrogates Fe-NTA induced hepatotoxicity in mice. Food Chem Toxicol. 2006;44(7):984-93.
40. Knas $M$, et al. Oxidative damage to the salivary glands of rats with streptozotocininduced diabetes-temporal study: Oxidative stress and diabetic salivary glands. J of Diabetes Research. 2016; $1-14$.

(c) 2017 Mahmoud and Mahmoud; This is an Open Access article distributed under the terms of the Creative Commons Attribution License (http://creativecommons.org/licenses/by/4.0), which permits unrestricted use, distribution, and reproduction in any medium, provided the original work is properly cited.

Peer-review history:

The peer review history for this paper can be accessed here:

http://sciencedomain.org/review-history/19579 